\title{
The Potential of a Mindfulness-Enhanced, Integrative Neuro-psychotherapy Program for Treating Fatigue Following Stroke: A Preliminary Study
}

\author{
Helene Hofer • Martin Grosse Holtforth • \\ Franziska Lüthy • Eveline Frischknecht • \\ Hansjörg Znoj • René M. Müri
}

Published online: 9 November 2012

(C) Springer Science+Business Media New York 2012

\begin{abstract}
Fatigue is a frequently reported symptom after a stroke. Although the phenomenology of poststroke fatigue is well known, clear definitions as well as diagnostic and therapeutic guidelines are missing. Poststroke fatigue can be regarded as a multidimensional phenomenon that might be influenced by neurological, physical, psychological, and cognitive factors. It can range from mild to severe and can affect every area of the activities of daily life. The objective of our preliminary study was to outline aspects of a specific treatment program for the management of poststroke fatigue. Eight patients were recruited for a mindfulnessenhanced, integrative neuropsychotherapy program. The treatment was a combination of neuropsychological interventions, psychoeducation, cognitive-behavioral therapy, and mindfulness techniques. The main treatment foci were (a) to facilitate an increased awareness of fatigue symptoms, (b) to help the patient detect and manage triggers of fatigue, and (c) to equip the patient with multiple self-help tools. Measures were assessed at the beginning, during, and at the end of treatment using self-assessment questionnaire for mental fatigue and related symptoms after neurological disorders and injuries. Significant pre- to post-assessment differences were observed. These findings suggest that patients
\end{abstract}

H. Hofer $(\bowtie) \cdot$ R. M. Müri

Department of Neurology, University of Bern, 3010 Bern, Switzerland

e-mail: helene.hofer@insel.ch

M. Grosse Holtforth

Department of Psychology, University of Zurich, 8050 Zurich, Switzerland

F. Lüthy $\cdot$ E. Frischknecht $\cdot$ H. Znoj

Department of Psychology, University of Bern,

3012 Bern, Switzerland may benefit from a specific treatment program in order to better adapt to poststroke fatigue. These findings encourage further investigation of this integrative treatment in larger samples that include adequate control treatments.

Keywords Poststroke fatigue $\cdot$ Cognitive behavioral therapy $\cdot$ Mindfulness $\cdot$ Psychoeducation $\cdot$ Stroke $\cdot$ Pilot study

\section{Introduction}

Fatigue is a frequently reported symptom after a stroke (Staub and Carota 2005; Stulemeijer et al. 2005). The percentages of stroke survivors reporting poststroke fatigue (PSF) range from 30 to $77 \%$ (Annoni et al. 2008; Christensen et al. 2008; Lerdal et al. 2009). PSF has been shown to be related to poor neurological recovery, low levels of activity in daily life, and lower quality of life (Choi-Kwon et al. 2005).

No consensual definition of the phenomenon of PSF exists in the literature (DeLuca 2005; Lynch et al. 2007). Fatigue after a stroke has been characterized as a latent dysfunction that is hard to detect by others and that is hard to predict due to the unknown, variable, or fluctuating capacities of the patients. Several dimensions have been proposed for the description of fatigue: objectively observable characteristics versus subjective experiences of fatigue, as well as physical, somatic, mental, or psychological symptoms of fatigue (Staub and Carota 2005). Staub and Bogousslavsky (2001) defined fatigue as "a reversible decrease or loss of abilities associated with a heightened sensation of physical or mental strain, even without conspicuous effort, an overwhelming feeling of exhaustion, 
which leads to inability or difficulty to sustain even routine activities and which is commonly expressed verbally as a loss of drive" (p. 76). Accordingly, PSF can be regarded as a multidimensional phenomenon that might be influenced by neurological, physical, psychological, and cognitive factors.

Both pharmacological (e.g., stimulants and antidepressants) and nonpharmacological (e.g., psychological training, cognitive behavior therapy, exercise training, and fatigue education) interventions have been proposed to treat PSF (De Groot et al. 2003; Lange et al. 2005). Among the nonpharmacological interventions, behavioral (e.g., psychoeducation of the patient and family members) and self-efficacy interventions (e.g., stress-management and coping skills) have been found beneficial (Barker-Collo et al. 2007; Cooper et al. 2009). Furthermore, an individually tailored approach was found to be most promising (Barker-Collo et al. 2007; Judd 1999; Lange et al. 2005). Zedlitz et al. (2011) proposed a cognitive and graded activity training to reduce PSF. But so far, the existing evidence seems insufficient to guide the clinical management of PSF (Barker-Collo et al. 2007; McGeough et al. 2009). To optimize treatment, several authors (Annoni et al. 2008; De Groot et al. 2003; Romani 2008; Staub and Carota 2005) have proposed that the treatment of PSF be based on a comprehensive assessment of fatigue (e.g., fatigue characteristics, predisposing factors as nutritional imbalance, sleep disorders, and emotional disturbance).

The objective of our preliminary study was to outline the central aspects of a specific treatment program for the management of PSF. This program is one component of a larger integrative neuropsychotherapy program. Based on our previous experience with the program, we expected that the mindfulness technique lead to an improvement regarding coping with PSF (differences between pre- and postmeasurements)

\section{Method}

\section{Participants}

The participants were recruited via the neurological-neuropsychological division of the University Hospital of Bern. All participants were outpatients and had completed intensive neuropsychological rehabilitation as inpatients, outpatients, or both, depending on their medical and neuropsychological needs. We included young and middle-aged stroke patients (Bigi et al. 2011; Nedeltchev et al. 2006). Exclusion criteria were: a prior history of neurological disease (such as a prior stroke), other chronically disabling pathologies (e.g., sarcoidosis), a progressive neurodegenerative illness, such as multiple sclerosis, or a prior history of mental disorders (including alcohol or drug abuse). The presence of a language disorder that caused comprehension deficits was an additional exclusion criterion.

A comprehensive neuropsychological examination (memory, attention, executive functioning, and visual functioning) of each participant was performed before the beginning of psychotherapy to ensure sufficient cognitive ability. This examination was usually conducted after the participant had completed a rehabilitation program. Patients presenting severe cognitive impairments were excluded from the study. Sufficient language ability to communicate and to understand information was checked using the Brief Aphasia Check List (Kalbe et al. 2005) and the Token Test (De Renzi and Vignola 1962).

\section{Measures}

We used the National Institutes of Health Stroke Scale (NIHSS) (Brott et al. 1989) to evaluate the effect of acute cerebral infarction on several functions (e.g., consciousness, physical functioning, and speech). The NIHSS is widely used to assess the severity of an acute ischemic stroke (Brott et al. 1989) and to predict stroke outcome (Adams et al. 1999; Appelros and Terent 2004; Frankel et al. 2000; Goldstein et al. 1989; Muir et al. 1996). The NIHSS can be used to scale patients retrospectively from chart records and can be applied reliably also by non-neurologists (Bushnell et al. 2001; Dewey et al. 1999; Kasner et al. 1999; Williams et al. 2000).

To assess the level of functioning and the independence of daily living, we used the extended scale for activities of daily living for stroke patients, that is, the Nottingham score (Nouri and Lincoln 1987) and an extended version of the Barthel Index (Prosiegel et al. 1996). The Nottingham score measures the patient's degree of independence as well as his or her ability to fulfill everyday tasks. The Barthel Index (Mahoney and Barthel 1965) is an objective tool assessing an individual's ability to perform the activities of daily living.

To assess mental fatigue, we used an adapted version of the self-assessment questionnaire for mental fatigue and related symptoms after neurological disorders and injuries (SQfMF) (Johansson et al. 2010). The questionnaire was administered before treatment, after ten sessions, and at the end of the treatment program.

\section{Neuro-psychotherapy Program}

The basic approach of the integrative neuro-psychotherapy program is that neuropsychological interventions will be combined with focused psychotherapeutic interventions. The goal is to optimally meet the special needs of this patient group by going beyond the measures applied in standard neurorehabilitation (cf. also Coetzer 2007). Based 
on therapy goals established at the outset, an individual treatment program will be carried out, with the main focus for each individual being clearly identified (e.g., memory, fatigue, etc.). The neuropsychological treatment contains solely the treatment of neuropsychological disorders caused by a stroke as well as their effects on everyday life. The interventions are based on conventional recommendations for neuropsychological outpatient rehabilitation (Cicerone et al. 2005; Sohlberg and Mateer 2001; Wilson 2003). According to Gauggel (2003), the goal of any neuropsychological rehabilitation is to treat the cognitive disorders presenting in order to achieve the highest possible functional level in everyday life. Furthermore, additional psychotherapeutic interventions, those also specifically focus on the emotional aspects of coping with the adjustment to the consequences of a stroke. The psychotherapeutic interventions will be adapted from cognitive-behavioral, emotionfocused, as well as interpersonal therapies (Dobson 2001; Greenberg 2002; Weissman et al. 2007). These psychological interventions will be carried out by trained psychotherapists and neuropsychologists on a one-to-one basis. Furthermore, all patients participated in a PSF rest management program. The duration of the treatment program was not limited a priori but instead adapted to suit each patient's individual needs. However, the general aim was to achieve the therapy goals within 20 sessions over the course of 1 year. Average session duration was $50 \mathrm{~min}$. At the beginning, a fatigue diary is introduced. The primary goal of sessions 1 to 5 is to implement and establish the PSF program. In the first session, we explained the log procedure. The patients are asked to log information every hour from 8.00 a.m. to 6.00 p.m. and at one point of time in the course of the evening. At these points of time, they are asked to note first the current activity, then to perform the body scan technique in order to note their bodily signs of fatigue, and finally to assess the level of subjective fatigue (for details, see Table 1). To assess the level of fatigue, we used an adapted version of the Visual Analogue Scale (Downie et al. 1978). As in the original scale, we used a continuous rating scale ranging from 1 (not at all tired) to 10 (intense tiredness). During each of the following four sessions, over a period of about 4 up to 6 weeks, patient and therapist evaluate the results of the log and discuss potential implications (e.g., application of relaxation exercises, etc.).

The duration of each session was approximately $50 \mathrm{~min}$. The main treatment foci were (a) to facilitate an increased awareness of fatigue symptoms, (b) to help the patient detect and manage triggers of fatigue, and (c) to equip the patient with multiple self-help strategies to successfully manage fatigue in order to maximize patient's performance in daily functioning (Barker-Collo et al. 2007; Colle et al. 2006; Cooper and Malley 2008). To raise the patient's awareness of bodily and mental signs, we used an intervention from mindfulness-based cognitive therapy, the so-called body scan technique (Segal et al. 2002). Among others, the body scan technique is used (a) to teach patients to become aware of early warning signs of tiredness and (b) to reduce tendencies to ignore these early signs. The information gathered then enabled patient and therapist to identify triggers and patterns of occurrence of fatigue. Using the body scan technique, the patient learned to identify strenuous activities and to determine the right time to take a break. To achieve an appropriate balance between rest and activity in daily living, patient and therapist defined the following major goals and strategies: (a) to prioritize and set realistic goals of what is achievable in a day; (b) to learn more about the mechanisms, triggers, and consequences of fatigue; (c) to formulate individualized rules for taking breaks (e.g., to take a break after lunch for no longer than $1 \mathrm{~h}$ or not to do more than two activities a day) and to identify which types of breaks are most helpful (e.g., naps or relaxation techniques) and less helpful (e.g., to watch television or to work at the computer); (d) to learn more about the association between tiredness and emotion regulation (e.g., increased tiredness may lead to reduced capacity to regulate emotions or worsening of mood may be a sign of increased tiredness); and (e) to acquire basic skills of emotion regulation (e.g., relaxation, mindfulness, and judgment-free cognition). In addition, the therapist taught rules of sleep hygiene (e.g., not to drink coffee in the evening) (Schepers et al. 2006). During the course of therapy, the use of the log book was adjusted to the patient's needs. Some patients became such good experts of themselves that they could stop using it, whereas others used it until the end of therapy. Having to cope with high degrees of fatigue was a recurring theme in therapy, we thus relied on the techniques introduced at the beginning of therapy and refined these to fit the patient's needs.

\section{Statistical Analyses}

Statistical analyses were performed using the STATISTICA software program of StatSoft (2001). Because the small sample size precluded assuming normally distributed data, nonparametric analyses were applied. The indicator rating approach of Wilcoxon's matched pairs test was used to evaluate the differences between pre- and post-measures. The total raw scores were used to compare the central tendencies of the SQfMF.

\section{Results}

In total, eight participants were recruited into the study (for details, see Table 2). These eight treated patients ranged in age from 20 to 61 years $(M=48)$, and five were men. Time since injury ranged from 4 to 65 months $(M=18)$. Two of 


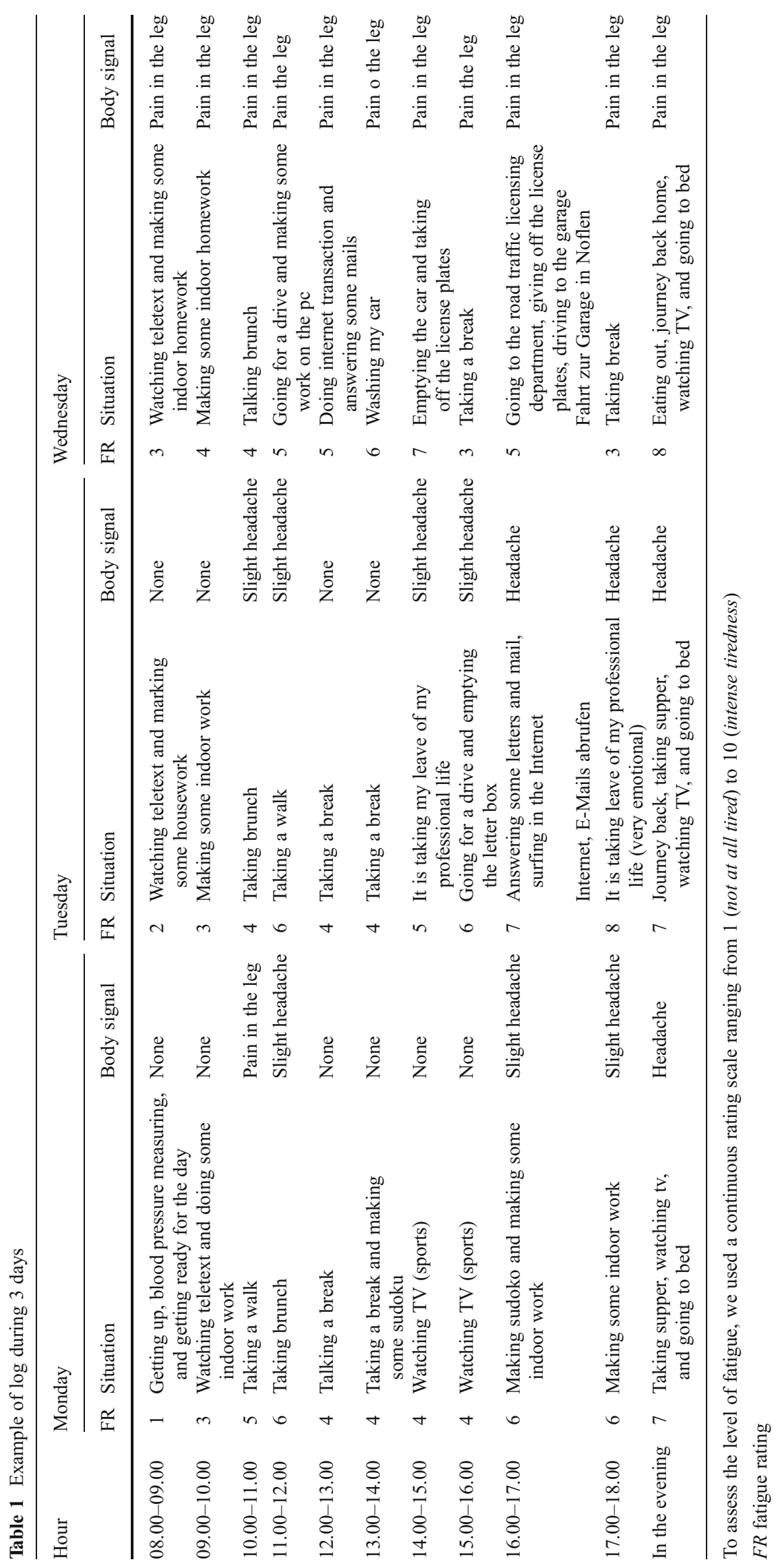


the participants had a stroke with hemorrhage and six a stroke with ischemia. The score of the NIHSS ranged from 5 to $13(\mathrm{M}=$ 8.1). Their Nottingham scores ranged from 19 to $22(\mathrm{M}=19)$. All participants lived at home. For detailed results, see Table 2.

Of the eight patients, only one patient had slight impairments in speech (amnesic aphasia). The other seven patients had several areas of impairments, ranging from slight to moderately impaired: five of the participants had neuropsychological impairments in attention, whereas four patients experienced impairments in executive functioning. Another three patients presented with memory problems and one with visual hemineglect and one patient with visual impairments (for details, see Table 3). All patients presented with a tendency to tire easily.

During the intervention phase, the eight patients received an average of 19 (range $=14-25$ ) therapy sessions. At the beginning of the therapy, the mean score of the SQfMF was 9.75 $(\mathrm{SD}=3.73$; range $=5-16)$. After ten sessions (progress measure), the mean score of the $\mathrm{SQfMF}$ was $8(\mathrm{SD}=4.2$; range $=4-16)$. There was no significant difference from pre- to progress. At the end of the therapy, a significant difference, however, emerged from pre- to posttreatment $(\mathrm{M}=5.88, \mathrm{SD}=3.18$, and range= $0-11 ; p<0.017)$. At the end of the therapy program, all patients indicated on the dichotomous item (yes or no) that they had achieved their individually formulated goals (in total, 27 goals), as defined by the GAS process (e.g., coping better with everyday limitations and coping better with increased tiredness).

\section{Discussion}

So far, PSF has received relatively little attention in the field of neurorehabilitation (Cooper et al. 2009). To a large degree, this cannot be attributed to its lack of clinical importance but rather to the complexity of the subject itself, its definition, the underlying disease mechanisms, and its assessment (DeLuca 2005; Jaracz et al. 2007; Zwarts et al. 2008). Several confounding factors may contribute to the symptomatology of PSF. Some are physiological factors, such as altered nutritional status and drug side effects; others are psychological factors, such as illness-

Table 2 Patient characteristics and clinical information

\begin{tabular}{ll}
\hline Age (M (range)) & $48(20-61)$ \\
Gender & 5 men and 3 women \\
Etiology & 2 with hemorrhage and \\
& 6 with ischemia \\
Time since injury in months (M (range)) & $18(4-65)$ \\
Number of therapy sessions (M (range)) & $19(14-25)$ \\
NIHSS (M (range)) & $8.1(5.0-13.0)$ \\
Nottingham score (M (range)) & $19(19-22)$ \\
Barthel score (M (range)) & $20(19-20)$ \\
\hline
\end{tabular}

NIHSS National Institutes of Health Stroke Scale
Table 3 Average of the neuropsychological data before treatment

\begin{tabular}{lll}
\hline Function/test & $\begin{array}{l}\text { Score }^{\mathrm{a}} \\
(\mathrm{M} \text { (range) })\end{array}$ & $\begin{array}{l}T \text { scores }^{\mathrm{b}} \\
(\mathrm{M} \text { (range) })\end{array}$ \\
\hline $\begin{array}{l}\text { Memory } \\
\quad \text { Rey Auditory Verbal Learning Test } \\
\quad \text { Helmstaedter, Lendt, \& Lux, 2001) }\end{array}$ & & \\
$\quad \begin{array}{l}\text { Learning total } \\
\text { Delayed recall }\end{array}$ & $54(38-68)$ & $51(35-58)$ \\
Rey-Osterrieth complex figure test & $12(9-15)$ & $52(42-59)$ \\
$\quad$ (Meyers and Meyers 1995) & & \\
$\quad$ Delayed recall (3 min) & $18(8.5-31)$ & $42(24-60)$ \\
Digit span (Härting et al. 2000) & $6(4-11)$ & $40(27-60)$
\end{tabular}

Attention

$\begin{array}{lcl}\begin{array}{c}\text { Trail-making test (s) (Oswald } \\ \text { and Roth 1987) }\end{array} & 81(39-103) & 45(37-53) \\ \text { Language screening errors } & 0(0-1) & -\end{array}$

(max. 40) (Kalbe et al. 2005)

Executive functioning

$\begin{array}{lcc}\begin{array}{l}\text { Word fluency (Aschenbrenner } \\ \text { et al. 2000) }\end{array} & 13(7-21) & 35(27-43) \\ \begin{array}{l}\text { Design fluency (Haid et al. 2002) } \\ \text { Inhibition (Delis et al. 2001) }\end{array} & 29(17-42) & 45(36-54) \\ \text { Seconds } & 60(40-87) & 47(32-60) \\ \text { Errors } & 1(0-5) & 54(45-60) \\ \text { Switching (Delis et al. 2001) } & & \\ \text { Seconds } & 67(53-76) & 49(36-60) \\ \text { Errors } & 2(1-5) & 49(38-53)\end{array}$

Visuospatial functioning

Rey-Osterrieth complex figure test copy 33 (30.5-36) 46 (35-52)

${ }^{\text {a }}$ Subtest scores are presented as nonstandardized raw scores

${ }^{\mathrm{b}}$ Subtest scores are converted to $T$ scores (mean $=50 ; \mathrm{SD}=10$ ) based on the normative data

related stress or comorbid mood disorders (De Groot et al. 2003; Lerdal et al. 2009; Staub and Carota 2005).

In this preliminary study, we investigated the changes in mindfulness-enhanced, integrative neuropsychotherapy program for treating fatigue following stroke. For our patients with PSF, the central goal was to learn better coping skills regarding their increased vulnerability to fatigue. The significant change in the symptoms of PSF as well as the achievement of the individually formulated therapy goals support the notion that these specific psychotherapeutic interventions foster the adjustment process to PSF. Given the multiple methodological limitations of this study, however, the results must be interpreted with caution.

To increase patient awareness of the signs of PSF, we used a component of MBCT, that is, the body scan technique (Segal et al. 2002). With the help of this technique, the patient 
learned to recognize the specific signs of fatigue and to distinguish between mental and physical fatigue. For our patients (as for most patients, according to our clinical experience) the concept of "mental fatigue" was vague and intangible at the beginning of the program. Whereas individuals without acquired brain injury usually do not need to become aware of mental fatigue or to make special efforts to recover, stroke patients develop mental fatigue more quickly, even after comparably "small" activities of daily living (e.g., brewing a cup of coffee). Whereas healthy individuals recover as part of automatized processes (e.g., within nightly sleep), for stroke patients the quantity, but also the form of regeneration may have changed. For example, reading an interesting book may no longer be recreational but may become an exhausting brain work. Consequently, patients face the challenge of learning to cope with PSF while keeping up as many of their daily activities as possible despite their fatigue.

Time seems to be an important factor. From baseline to the tenth session, no significant change could be detected. It is only at the end of treatment that this change was observed, which is in keeping with Cooper et al.'s (2009) notion that change requires a certain amount of time. Our results are also congruent with Howard et al.'s (1986) findings, which show that also in psychotherapy the process of change takes time: on average, $50 \%$ of patients with common psychological disorders improved significantly after only 8 sessions of psychotherapy while $75 \%$ of patients showed an improvement after 26 sessions. Further studies are needed to determine exactly how many sessions our patients need in order to establish an optimal rest management program for themselves.

Furthermore, we assume that the PSF rest management program may have an important side effect: participating in this program and implementing its rules may also increase levels of perceived competence. Feelings of competence assumedly satisfy a basic psychological need of being in control, having an orientation, and experiencing coherence in life. According to both Epstein's (1990) cognitive experiential self-theory and Grawe's (2007) consistency theory, the satisfaction of these psychological needs is central to human well-being. According to consistency theory, insufficient satisfaction of psychological needs may give rise to psychopathology as well as low levels of well-being. A stroke may understandably results in the violation of basic human needs for control, orientation, and coherence. After a stroke, a patient may experience loss of control, oftentimes he or she does not spontaneously understand the implications of the stroke for daily living, and the patient is inexperienced with regard to handling the newly acquired limitations. Thus, learning ways to deal with this condition may help to restore feelings of competence and control. In addition, increased self-efficacy has been shown to correlate with mental health and well-being in stroke patients, and in people in general (Bandura 1997; Gracey et al. 2008). Further research is necessary to test this assumption.
This study has several limitations. A crucial point is the rest management program was one part of a larger therapeutic program. In that sense, it is not possible to differentiate the effects of the mindfulness intervention from the larger neuropsychotherapy program. Thus, we can assume that the other interventions (e.g., activation of patients' strengths and elaborating compensatory strategies to cope with cognitive impairments) have had a positive impact of the rest management program. The specific effects of the mindfulness interventions need to be examined in future studies using a dismantling design, i.e., comparing identical treatments with or without mindfulness interventions.

A further limitation is the use of paper diaries. The compliance with diary assignments seems to be critical. Green et al. (2006) discussed in their paper comparing paper and electronic diaries that there exists "at least partially mollify concern about the validity of paper diary methods" (p. 87). We made effort for enhancing acceptance and completion of homework assignments to create sufficient motivation (Green et al. 2006). Nevertheless, we did not control the homework compliance. There seems to be a correlation between the compliance of homework assignments and the outcome of the therapy (Helbig and Fehm 2005). Further research is needed to verify the validity of paper diaries in contrast to electronic diaries in this specific population.

Moreover, due to the small sample size and the lack of a control group, the current findings should be viewed as preliminary. We suggest that this program should not be restricted to stroke patients, only. Further studies with larger patient samples and inclusion of other neurological populations with similar clinical problems (e.g., traumatic brain injury) are required to test the effects of our rest management program and to clarify the relationship between PSF and the emotional and cognitive sequelae caused by an ABI.

\section{References}

Adams, H. P., Jr., Davis, P. H., Leira, E. C., Chang, K. C., Bendixen, B. H., Clarke, W. R., et al. (1999). Baseline NIH Stroke Scale score strongly predicts outcome after stroke: a report of the Trial of Org 10172 in Acute Stroke Treatment (TOAST). Neurology, 53, 126131.

Annoni, J. M., Staub, F., Bogousslavsky, J., \& Brioschi, A. (2008). Frequency, characterisation and therapies of fatigue after stroke. Neurological Sciences, 29(Suppl 2), S244-S246. doi:10.1007/ s10072-008-0951-0.

Appelros, P., \& Terent, A. (2004). Characteristics of the National Institute of Health Stroke Scale: results from a population-based stroke cohort at baseline and after 1 year. Cerebrovascular Diseases, 17, 21-27. doi:10.1159/000073894/73894.

Aschenbrenner, S., Tucha, O., \& Lange, K. W. (2000). Regensburger Wortflüssigkeits-Test-RWT [Regensburger Oral Word Association Test]. Göttingen: Hogrefe.

Bandura, A. (1997). Self-efficacy: the exercise of control. New York: Freeman. 
Barker-Collo, S., Feigin, V. L., \& Dudley, M. (2007). Post-stroke fatigue - where is the evidence to guide practice. The New Zealand Medical Journal, 120, 1-9.

Bigi, S., Fischer, U., Wehrli, E., Mattle, H. P., Boltshauser, E., Burki, S., et al. (2011). Acute ischemic stroke in children versus young adults. Annual Neurology, 70, 245-254. doi:10.1002/ana.22427.

Brott, T., Adams, H. P., Jr., Olinger, C. P., Marler, J. R., Barsan, W. G., Biller, J., et al. (1989). Measurements of acute cerebral infarction: a clinical examination scale. Stroke, 20, 864-870.

Brott, T., Marler, J. R., Olinger, C. P., Adams, H. P., Jr., Tomsick, T., Barsan, W. G., et al. (1989). Measurements of acute cerebral infarction: lesion size by computed tomography. Stroke, 20, 871-875.

Bushnell, C. D., Johnston, D. C., \& Goldstein, L. B. (2001). Retrospective assessment of initial stroke severity: comparison of the NIH Stroke Scale and the Canadian Neurological Scale. Stroke, $32,656-660$

Choi-Kwon, S., Han, S. W., Kwon, S. U., \& Kim, J. S. (2005). Poststroke fatigue: characteristics and related factors. Cerebrovascular Diseases, 19, 84-90.

Christensen, D., Johnsen, S. P., Watt, T., Harder, I., Kirkevold, M., \& Andersen, G. (2008). Dimensions of post-stroke fatigue: a twoyear follow-up study. Cerebrovascular Diseases, 26, 134-141. doi: $10.1159 / 000139660$

Cicerone, K. D., Dahlberg, C., Malec, J. F., Langenbahn, D. M., Felicetti, T., Kneipp, S., et al. (2005). Evidence-based cognitive rehabilitation: updated review of the literature from 1998 through 2002. Archives of Physical Medicine and Rehabilitation, 86, $1681-1692$

Coetzer, R. (2007). Psychotherapy following traumatic brain injury: integrating theory and practice. The Journal of Head Trauma Rehabilitation, 22, 39-47.

Colle, F., Bonan, I., Gellez Leman, M. C., Bradai, N., \& Yelnik, A. (2006). Fatigue after stroke. Annales de Réadaptation et de Médecine Physique, 49(272-276), 274-361. doi:10.1016/ j.annrmp.2006.04.009.

Cooper, J., \& Malley, D. (2008). Managing fatigue after brain injury. Nottingham: Headway-The Brain Injury Association.

Cooper, J., Reynolds, F., \& Bateman, A. (2009). An evaluation of a fatigue management intervention for people with acquired brain injury: an exploratory study. British Journal of Occupational Therapy, 72, 174-179.

De Groot, M. H., Phillips, S. J., \& Eskes, G. A. (2003). Fatigue associated with stroke and other neurologic conditions: implications for stroke rehabilitation. Archives of Physical Medicine and Rehabilitation, 84, 1714-1720.

De Renzi, E., \& Vignola, L. A. (1962). The Token Test. A sensitive test to detect receptive disturbances in aphasics. Brain, 85, 665-678.

Delis, D. C., Kaplan, E., \& Kramer, J. H. (2001). Delis-Kaplan Executive Function System-D-KEFS. San Antonio: The Psychological Corporation

DeLuca, J. (2005). Fatigue as a window to the brain. Cambridge: Massachusetts Institute of Technology.

Dewey, H. M., Donnan, G. A., Freeman, E. J., Sharples, C. M., Macdonell, R. A., McNeil, J. J., et al. (1999). Interrater reliability of the National Institutes of Health Stroke Scale: rating by neurologists and nurses in a community-based stroke incidence study. Cerebrovascular Diseases, 9, 323-327.

Dobson, K. S. (2001). Handbook of cognitive-behavioral therapies (2nd ed.). New York: Guilford.

Downie, W. W., Leatham, P. A., Rhind, V. M., Wright, V., Branco, J. A., \& Anderson, J. A. (1978). Studies with pain rating scales. Annals of the Rheumatic Diseases, 37, 378-381.

Epstein, S. (1990). Cognitive-experiential self-theory. In L. A. Pervin (Ed.), Handbook of personality: theory and research (pp. 165192). New York: Guilford.
Frankel, M. R., Morgenstern, L. B., Kwiatkowski, T., Lu, M., Tilley, B. C., Broderick, J. P., et al. (2000). Predicting prognosis after stroke: a placebo group analysis from the National Institute of Neurological Disorders and Stroke rt-PA Stroke Trial. Neurology, $55,952-959$.

Gauggel, S. (2003). The theoretical and empirical foundation of neuropsychological treatment: neuropsychotherapy or brain jogging? (author's transl.). Zeitschrift fuer Neuropsychologie, 14, 217-246.

Goldstein, L. B., Bertels, C., \& Davis, J. N. (1989). Interrater reliability of the NIH stroke scale. Archives of Neurology, 46, 660-662.

Gracey, F., Palmer, S., Rous, B., Psaila, K., Shaw, K., O'Dell, J., et al. (2008). "Feeling part of things": personal construction of self after brain injury. Neuropsychological Rehabilitation, 18, 627-650. doi:10.1080/09602010802041238.

Grawe, K. (2007). Neuropsychotherapy: How the neurosciences inform effective psychotherapy. Florence: Lawrence Erlbaum Associates.

Green, A. S., Rafaeli, E., Bolger, N., Shrout, P. E., \& Reis, H. T. (2006). Paper or plastic? Data equivalence in paper and electronic diaries. Psychological Methods, 11, 87-105. doi:10.1037/1082989X.11.1.87.

Greenberg, L. (2002). Emotion-focused therapy: coaching clients to work through feelings. Washington: American Psychological Association.

Haid, T., Martl, C., Schubert, F., Wenzl, M., Kofler, M., \& Saltuari, L. (2002). Der HAMASCH 5 Punkt Test. Erste Normierungsergebnisse. [The HAMASCH five point test. Preliminary norm data.]. Zeitschrift für Neuropsychologie, 13, 233.

Härting, C., Markowitsch, H. J., \& Neufeld, H. (2000). Wechsler Gedächtnistest-Revidierte Fassung WMS-R [German adaption of the Wechsler Adult Intelligence Test—-text memory]. Bern: Hans Huber.

Helbig, S., \& Fehm, L. (2005). Der Einsatz von Hausaufgaben in der Psychotherapie. Empfehlungen und ihre empirische Fundierung. [Homework recommendations in theory and research. Empirical results on the recommended use of homework.]. Psychotherapeut, $50,122-128$.

Helmstaedter, C., Lendt, M., \& Lux, S. (2001). Verbaler Lern- und Merkfähigkeitstest_VLMT [Verbal Learning and Memory Test]. Göttingen: Beltz.

Howard, K. I., Kopta, S. M., Krause, M. S., \& Orlinsky, D. E. (1986). The dose-effect relationship in psychotherapy. American Psychologist, 41, 159-164.

Jaracz, K., Mielcarek, L., \& Kozubski, W. (2007). Clinical and psychological correlates of poststroke fatigue. Preliminary results. Neurologia i Neurochirurgia Polska, 41, 36-43.

Johansson, B., Starmark, A., Berglund, P., Rodholm, M., \& Ronnback, L. (2010). A self-assessment questionnaire for mental fatigue and related symptoms after neurological disorders and injuries. Brain Injury, 24, 2-12. doi:10.3109/02699050903452961.

Judd, T. (1999). Neuropsychotherapy and community integration. New York: Kluwer Academic/Plenum Publishers.

Kalbe, E., Reinhold, N., Brand, M., Markowitsch, H. J., \& Kessler, J. (2005). A new test battery to assess aphasic disturbances and associated cognitive dysfunctions - German normative data on the aphasia check list. Journal of Clinical and Experimental Neuropsychology, 27, 779-794.

Kasner, S. E., Chalela, J. A., Luciano, J. M., Cucchiara, B. L., Raps, E. C., McGarvey, M. L., et al. (1999). Reliability and validity of estimating the NIH stroke scale score from medical records. Stroke, 30, 1534-1537.

Lange, G., Cook, D. B., \& Natelson, B. H. (2005). Rehabilitation and treatment of fatigue. In J. DeLuca (Ed.), Fatigue as a window to the brain (pp. 301-316). Cambridge: Massachusetts Institute of Technology. 
Lerdal, A., Bakken, L. N., Kouwenhoven, S. E., Pedersen, G., Kirkevold, M., Finset, A., et al. (2009). Poststroke fatigue - a review. Journal of Pain and Symptom Management, 38, 928-949.

Lynch, J., Mead, G., Greig, C., Young, A., Lewis, S., \& Sharpe, M. (2007). Fatigue after stroke: the development and evaluation of a case definition. Journal of Psychosomatic Research, 63, 539-544.

Mahoney, F. I., \& Barthel, D. W. (1965). Functional evaluation: the Barthel Index. Maryland State Medical Journal, 14, 61-65.

McGeough, E., Pollock, A., Smith, L. N., Dennis, M., Sharpe, M., Lewis, S., \& Mead, G. E. (2009). Interventions for post-stroke fatigue. Cochrane Database Systematic Reviews, CD007030. doi:10.1002/14651858.CD007030.pub2

Meyers, J. E., \& Meyers, K. (1995). The Meyers scoring system for the Rey complex figure and the recognition trial: professional manual. Odessa: Psychological Assessment Resources.

Muir, K. W., Weir, C. J., Murray, G. D., Povey, C., \& Lees, K. R. (1996). Comparison of neurological scales and scoring systems for acute stroke prognosis. Stroke, 27, 1817-1820.

Nedeltchev, K., Fischer, U., Arnold, M., Ballinari, P., Haefeli, T., Kappeler, L., et al. (2006). Long-term effect of intra-arterial thrombolysis in stroke. Stroke, 37, 3002-3007. doi:10.1161/ 01.STR.0000249417.24085.80.

Nouri, F. M., \& Lincoln, N. B. (1987). An extended activity of daily living scale for stroke patients. Clinical Rehabilitation, 1, 301305 .

Oswald, W. D., \& Roth, E. (1987). Zahlenverbindungstest (ZVT) [Trail Making Test]. Göttingen: Verlag für Psychologie Hogrefe.

Prosiegel, M., Boettger, S., Schenk, T., Koenig, N., Marolf, M., Vaney, C., et al. (1996). Der Erweiterte Barthel-Index (EBI) - eine neue Skala zur Erfassung von Faehigkeitsstoerungen bei neurologischen Patienten. [The extended Barthel Index (EBI): a new scale for the assessment of disability in neurological patients]. Neurologie \& Rehabilitation, 2, 7-13.

Romani, A. (2008). The treatment of fatigue. Neurological Sciences, 29(Suppl 2), S247-S249. doi:10.1007/s10072-008-0952-Z.
Schepers, V. P., Visser-Meily, A. M., Ketelaar, M., \& Lindeman, E. (2006). Poststroke fatigue: course and its relation to personal and stroke-related factors. Archives of Physical Medicine and Rehabilitation, 87, 184-188. doi:10.1016/j.apmr.2005.10.005.

Segal, Z. V., Williams, J. M. G., \& Teasdale, J. D. (2002). Mindfulnessbased cognitive therapy for depression: a new approach to preventing relapse. New York: Guilford Press.

Sohlberg, M. M., \& Mateer, C. A. (2001). Cognitive rehabilitation. An integrative neuropsychological approach. New York: Guilford Press.

StatSoft, I. (2001). STATISTICA for Windows [Computer program manual]. Tulsa: StatSoft, Inc. Available from http:// www.statsoft.com

Staub, F., \& Bogousslavsky, J. (2001). Fatigue after stroke: a major but neglected issue. Cerebrovascular Diseases, 12, 75-81.

Staub, F., \& Carota, A. (2005). Depression and fatigue after stroke. In M. Barnes, B. Dobkin, \& J. Bogousslavsky (Eds.), Recovery after stroke. Cambridge: Cambridge University Press.

Stulemeijer, M., Fasotti, L., \& Bleijenberg, G. (2005). Fatigue after stroke. In J. DeLuca (Ed.), Fatigue as a window to the brain (pp. 73-88). Cambridge: Massachusetts Institute of Technology.

Weissman, M. M., Markowitz, J. C., \& Klerman, G. L. (2007). Clinican's quick guide to interpersonal psychotherapy. New York: Oxford University Press.

Williams, L. S., Yilmaz, E. Y., \& Lopez-Yunez, A. M. (2000). Retrospective assessment of initial stroke severity with the NIH Stroke Scale. Stroke, 31, 858-862.

Wilson, B. A. (2003). Neuropsychological rehabilitation: theory and practice. Lisse: Swets \& Zeitlinger.

Zedlitz, A. M., Fasotti, L., \& Geurts, A. C. (2011). Post-stroke fatigue: a treatment protocol that is being evaluated. Clinical Rehabilitation, 25, 487-500.

Zwarts, M. J., Bleijenberg, G., \& van Engelen, B. G. (2008). Clinical neurophysiology of fatigue. Clinical Neurophysiology, 119, 2-10. doi:10.1016/j.clinph.2007.09.126. 